\title{
The chemical ecology of Harmonia axyridis
}

\author{
John J. Sloggett ${ }^{*}$, Alexandra Magro ${ }^{2,3}$, François J. Verheggen ${ }^{4}$, Jean-Louis \\ Hemptinne $^{2,3}$, William D. Hutchison ${ }^{5}$, Eric W. Riddick ${ }^{6}$ \\ ${ }^{1}$ Faculty of Biological Sciences, University of South Bohemia, Branišovská 31, 37005 České \\ Budějovice, Czech Republic. ${ }^{2}$ Université de Toulouse, ENFA, EDB (Laboratoire Evolution et \\ Diversité Biologique), 2 route de Narbonne, 31320 Castanet Tolosan, France. ${ }^{3}$ CNRS, EDB \\ (Laboratoire Evolution et Diversité Biologique), 31062 Toulouse, France. ${ }^{4}$ Gembloux Agro- \\ Bio Tech, Liege University, Passage des Déportés 2, 5030 Gembloux, Belgium. ${ }^{5}$ Department \\ of Entomology, University of Minnesota, 219 Hodson Hall, 1980 Folwell Avenue, St. Paul, \\ MN 55108, USA. ${ }^{6}$ National Biological Control Laboratory, USDA-Agricultural Research \\ Service, Stoneville, MS 38776, USA \\ *Corresponding author, current address: Maastricht Science Programme, Maastricht \\ University, P.O. Box 616, 6200 MD Maastricht, The Netherlands. E-mail: \\ j.sloggett@maastrichtuniversity.nl
}

In the recent SI of BioControl and resultant book from this working group (Roy et al., 2012), we contributed a review paper on the chemical ecology of the invasive aphidophagous ladybird Harmonia axyridis (Sloggett et al., 2011). This paper focused on both the pure and applied aspects of this subject, including sections on: (1) chemical defence; (2) foods, feeding and reproduction; (3) H. axyridis chemistry, humans and human activity, and (4) future research perspectives.

Harmonia axyridis' chemical defence is comprised of two alkaloids (harmonine and 3-hydroxypiperidin-2-one) and four methoxypyrazines. Based on assays of palatability and toxicity, it appears to be one of the most powerful chemical defence blends amongst ladybirds. There is some evidence that both harmonine and methoxypyrazine concentrations vary predictably with ladybird colour and pattern, although no such work has been carried out for 3-methoxypiperidin-2-one. Since our original review was published, the alkaloid harmonine has been shown to be a broad spectrum anti-microbial and powerful anti-malarial compound (Rörich et al., 2012).

Our knowledge of food location in $H$. axyridis remains poor, although the ladybird appears to use multimodal cues, probably including chemical ones from both host plant and aphid prey. Like many other ladybirds, $H$. axyridis is deterred from oviposition by conspecific larval chemical cues. It is not deterred from oviposition by chemical cues from allospecifics, although in its native range other ladybird species avoid such cues from $H$. axyridis. This behaviour probably serves these species as a means of avoiding $H$. axyridis intraguild predation. Generally, $H$. axyridis ignores the deterrent hydrocarbon cues on the surface of ladybird egg intraguild prey and is little affected by intraguild prey defensive alkaloids, although a number of exceptions are known, especially in its invasive range.

The habit of $H$. axyridis overwintering in large aggregations in buildings is not limited to its invasive range, although in its native range, such aggregations tend to be of very limited duration. Aggregations in buildings cause numerous problems, including the spotting of furnishings from reflex blood, allergic reactions in humans using the buildings and risks posed to pets or even children that may eat the ladybirds. Another problem caused by the abundance of $H$. axyridis is "wine taint", predominantly from methoxypyrazines, when the ladybirds are attracted to grape crops in autumn and are harvested and processed with the 
fruit. Close monitoring of numbers of ladybirds in the grape crop before harvesting and, if necessary, chemical control, are necessary to reduce or eliminate this problem. A number of chemicals or other baits have been suggested as repellents or attractants in order to better manange $H$. axyridis populations, although published work thus far has been largely restricted to the laboratory. Two unpublished field trials of chemical attractants in Europe, postdating the publication of our review, have proved unsuccessful.

One focus for future work is intraspecific chemical communication. Chemicals responsible for aggregation are of great applied importance. A hitherto unworked on, but particularly interesting subject for investigation, is the possible use of chemical cues in kin recognition to avoid the cannibalism of close relatives. Further work on chemical defence is particularly required on the "ignored" alkaloid 3-hydroxypiperidin-2-one, for which a new more user-friendly and memorable name, axyridine, is proposed. Similarly, studies on chemical aspects of $H$. axyridis' foraging and reproductive behaviour may reveal differences compared to other ladybirds, due to its presumed polyphagy and possible role as a top predator in aphidophagous communities. Further field trials of attractants and repellents are required.

\section{Acknowledgements}

The presentation of our review at the working group meeting and the extended abstract given here were supported by grant number QH82047 from the Ministry of Agriculture of the Czech Republic.

\section{References}

Rörich, C. R., Ngwa, C. J., Wiesner, J., Schmidtberg, H., Degenkolb, T., Kollewe, C., Fischer, R., Pradel, G. \& Vilcinskas, A. 2012: Harmonine, a defence compound from the harlequin ladybird, inhibits mycobacterial growth and demonstrates multi-stage antimalarial activity. Biol. Lett. 8: 308-311.

Roy, H. E., De Clercq, P., Lawson Handley, L.-J., Sloggett, J. J., Poland, R. L. \& Wajnberg, E. (eds.) 2012: Invasive Alien Arthropod Predators and Parasitoids: an Ecological Approach. Springer, Dordrecht.

Sloggett, J. J., Magro, A., Verheggen, F. J., Hemptinne, J.-L., Hutchison, W. D. \& Riddick, E. W. 2011: The chemical ecology of Harmonia axyridis. BioControl 56: 643-661. 